\title{
FACTORS ASSOCIATED WITH BODY MASS INDEX IN CHILDREN - A COMMUNITY-BASED STUDY
}

\section{NIKHILA PALADUGU ${ }^{1}$, RAMAKRISHNA RAYITI ${ }^{1}$, SIDDHARTHA NUTAKKI ${ }^{1}$, RAJASREE GADDE ${ }^{1}$, SAILAJA K ${ }^{2}$, VIJAYA KUMAR GHANTA ${ }^{1}$, VISWA SRUJANI KANAGALA ${ }^{*}$}

${ }^{1}$ Department of Pharmacy Practice, KVSR Siddhartha College of Pharmaceutical Sciences, Vijayawada, Andhra Pradesh, India. ${ }^{2}$ Department of Pediatrics, Dr. Pinnamaneni Siddhartha Institute of Medical Sciences and Research Foundation, Krishna, Andhra Pradesh, India. Email: kvsrujani@gmail.com

Received: 23 November 2020, Revised and Accepted: 25 December 2020

\section{ABSTRACT}

Objectives: The increasing prevalence of overweight, obesity, and underweight in children has implications for their future health and it is vital to understand the modifiable factors that contribute to it. The study's main objective is to determine the factors associated with the body mass index in children.

Methods: A cross-sectional study was conducted among 346 school children over a period of 6 months. Data were collected using self-administered questionnaire. Physical measurements such as height and weight were obtained from parents. BMI (Body Mass Index) was calculated using kg/m². Children were categorized as overweight, obese, normal, and underweight using their body mass index scores and the factors associated with BMI in children were estimated.

Results: The prevalence of overweight, obesity, normal, and underweight among children was $10.40 \%, 17.92 \%, 24.28 \%$, and $41.67 \%$, respectively. Intake of fast food, sweetened beverages, junk food, and consumption of food while watching television, media time indicated a significant relationship with body mass index.

Conclusion: Health care professionals should educate parents and children regarding healthy nutrition and regular physical activity. The implications of obesity, overweight, and underweight should be well explained to make desirable lifestyle modifications for a better future.

Keywords: Body mass index, Obesity, Overweight, Underweight, Children, Factors.

(C) 2021 The Authors. Published by Innovare Academic Sciences Pvt Ltd. This is an open access article under the CC BY license (http://creativecommons.org/ licenses/by/4.0/) DOI: http://dx.doi.org/10.22159/ajpcr.2021v14i1.40318. Journal homepage: https://innovareacademics.in/journals/index.php/ajpcr

\section{INTRODUCTION}

The rising preponderance of overweight and obesity in childhood has leading inferences for their present and future health. An energy imbalance between calories consumed and calories expended is the well-known cause of overweight and obesity in children [1]. However, increasing evidence indicates that the notion of calorie imbalance may not be enough to handle and reverse the epidemic of obesity [2]. Complications of underweight and overweight can influence the physical growth and psychological development of children. Similarly, those children have high risks of hypertension, type-2 diabetes mellitus, metabolic, and mental disorders [3]. Consumption of high-fat foods is not only a reason for increased BMI, but lack of physical activity will also play a key role in the energy balance equation. Nowadays, children have more addictions to television, video games, and social websites than to exercise or play outdoors at their leisure [4]. Childhood obesity can be tackled through education, prevention, and viable interventions related to healthy dietary practices and promotion of physical activity at a population level.

To be reliable, these preventive tactics require effective tools to determine parameters such as the cutoff value or weight category to be considered for early diagnosis [5]. BMI is a simple and extensively used screening tool for child and adult obesity [6]. It is defined as the weight in kilograms divided by the square of the height in meters $\left(\mathrm{kg} / \mathrm{m}^{2}\right)$ [7]. BMI is not only used as an outcome measure for determining obesity but also as a useful anthropometric index for cardiovascular risk [5]. Exercise regimens alone will not work without food modification, as higher energy expenditure is likely to match higher energy intakes [8].
Poor nutritional choices, which include high soft drinks, sweets, snacks, takeaway foods, and large portions of food, were associated with increased BMI in adults, children, and adolescents [9]. The range of factors involved in the body mass index should be fully characterized and investigated to address this global problem [10].

Increasing fast food prices and decreasing healthy food prices can encourage healthy food consumption [11]. Sweetened beverages add calories and sugar but no nutritional value. Increased calorie intake is a major contributor to the recent increase in obesity [12]. Some studies suggest that the recommendation for consumption of fruit and vegetables can be justified but should not be based on a desirable weight regulation effect [13]

If society focuses on the causes, the rising problem of childhood obesity can be slowed down. Many variables play into obesity in the adolescence, some of which are more crucial than others. Focusing on these causes can alleviate childhood obesity over time and yield to a healthier society as a whole [14].

This study aimed to determine the association of some well-known factors such as fast food, sweetened beverages, television viewing, media time, physical activity, and sleep with body mass index in children

\section{METHODS}

This is a cross-sectional study investigating the prevalence and the factors associated with the body mass index in children. Data were collected through the self-administered questionnaire with in the 
period of 6 months in children from the age group of 6-12 years. The questionnaire contains the information about child's demographics, food habits, physical activity status, and health and lifestyle information. The children's questionnaires were completed by their parents after obtaining the consent.

To calculate the BMI, parents were asked to report the height and weight of their children. For some children height and weight were measured objectively, although there were no standardized instructions for this. BMI was calculated (weight $[\mathrm{kg}] /$ height $[\mathrm{m}]^{2}$ ). According to the WHO, normal BMI was $18.5-24.9 \mathrm{~kg} / \mathrm{m}^{2}$ and less than $18.5 \mathrm{~kg} / \mathrm{m}^{2}$ are said to be underweight, within the range of $25-30 \mathrm{~kg} / \mathrm{m}^{2}$ are said to be overweight, greater than $30 \mathrm{~kg} / \mathrm{m}^{2}$ are said to be obese [7]. After refining the collected data, 346 children were included in the study and 54 were excluded from the study due to insufficient information provided and also ambiguous answers for some questions.

\section{Statistical analysis}

In the descriptive statistical analysis, the categorical variables were expressed by percentages. The univariate analysis was done using Chisquare test to determine the strength of association between factors and BMI, and the odds ratio was calculated and presented. For all analyses, $p<0.05$ was regarded as statistically significant. Data were analyzed using statistical tools like Epi-info 7.0 and GraphPad prism version 5.0

\section{Ethical consideration}

The study protocol has been approved by Dr. Pinnamaneni Siddhartha Institute of Medical Sciences and Research Foundation's Institutional Ethics Committee. Before initiating the study, all participants were informed and consent was obtained.

\section{RESULTS}

\section{Characteristics of study participants}

Table 1 shows the characteristics of children who participated in the study. A total of 346 children were included and in that $17.9 \%$ were found to be obese, $10.4 \%$ were overweight, $47.4 \%$ were underweight, and the remaining had normal BMI (24.2\%).

When compared to boys the percentage of girls who were overweight and obese (58.3\% vs. $41.6 \%$ and $67.7 \%$ vs. $32.2 \%$ ) was greater. Whereas in the case of children who were underweight or had normal BMI $50 \%$ were boys and $50 \%$ were girls. About $32 \%$ of the children who participated in the study were 6-7 years old, $34.6 \%$ were from the age group $8-9$ years, $28.6 \%$ were from 10 to 11 years age group, and $4.6 \%$ were 12 years old.

The BMI values of the children who participated in the study, classified in accordance with age, are given in Table 1; here, it can be observed that majority of the children from 6-7, 8-9, and 10-11 age groups were underweight $(n=54,51,54)$ when compared to other categories, that is, overweight $(n=8,13,12)$, obese $(n=26,28,8)$, and normal $(n=22,28,26)$, respectively. On the other hand, normal BMI $(n=8)$ was found to be greater among 12-year-old children when compared to underweight $(\mathrm{n}=5)$ and overweight $(\mathrm{n}=3)$.

Factors associated with obesity, overweight, and underweight in children aged $6-12$ years

Fast (processed) food

From Table 2, consumption of fast food is highly significant (with increasing servings/week) among obese children (more than 3 times/week ([p<0.0001], OR 133, 95\% CI=12.7-1391); 1-2 times/week ( $[\mathrm{p}=0.0002]$, OR 31.6, 95\% CI=3.3-301); and occasional ( $[\mathrm{p}=0.0081]$, OR 10.1, 95\% $\mathrm{CI}=1.29-71.8)\}$. In children, classified as overweight according to their BMI, fast food consumption is found to be significant \{more than 3 times/ week ([p=0.01], OR 7.91, 95\% CI=1.3-47.5); $1-2$ times/week ( $[\mathrm{p}=0.0003]$, OR $11.8,95 \% \mathrm{CI}=2.8-49.8)\}$. Occasional fast food consumption is found to have no significant association with overweight. Consumption of fast-food 1-2 times/week is highly significant among underweight children.

\section{Sweetened beverages}

From Table 2, consumption of sweetened beverages is highly significant among obese children \{more than 3 times/week ([p<0.0001], OR 32.0, 95\% $\mathrm{CI}=8.0-128) ; 1-2$ times/week ( $[\mathrm{p}<0.0001]$, OR 13.3, 95\% CI=3.37-52.7); and occasional $([\mathrm{p}<0.0001]$, OR 14.04, 95\% CI=3.70-53.1)\}. Drinking sweetened beverages occasionally (or) 1-2 times/week is found to be significant among the overweight \{occasional ( $[\mathrm{p}=0.0002]$, OR 7.57, 95\% $\mathrm{CI}=2.4-23.5)$; $1-2$ times/week ( $[\mathrm{p}=0.0024]$, OR 5.86, 95\% CI=1.7-19.7)\}. Similar significant associations are observed among the children who belong to the underweight category \{occasional ( $[\mathrm{p}<0.0001]$, OR 7.48, 95\% $\mathrm{CI}=3.74-14.9)$; $1-2$ times/week ( $[\mathrm{p}=0.004]$, OR 3.06, 95\% CI=1.39-6.7)\}.

\section{Junk (unhealthy) food}

From Table 2, consumption of junk food is found to be highly significant among underweight children \{occasional $([\mathrm{p}<0.0001]$, OR 39.0, 95\% $\mathrm{CI}=4.4-341.7) ; 1-2$ times/week $([\mathrm{p}<0.0001]$, OR 35.0, 95\% $\mathrm{CI}=4.1-$ 292.1); more than 3 times/week ( $[\mathrm{p}=0.0024]$, OR 13.2, 95\% CI=1.6107.4)\} Significant associations are observed between consumption of junk food and obesity \{occasional ( $[\mathrm{p}=0.01]$, OR 5.0, 95\% CI=1.2-20); $1-2$ times/week $([\mathrm{p}=0.03]$, OR $3.88,95 \% \mathrm{CI}=1.05-14.3)\}$ as well as overweight \{occasional ( $[\mathrm{p}=0.01]$, OR 18.7, 95\% CI=1.0-345.3)\}.

\section{Vegetables}

Consumption of vegetables more than 3 times/week reduces the risk of children becoming obese. $\{(\mathrm{p}=0.004), \mathrm{OR} 0.34,95 \% \mathrm{CI}=0.16-0.73\}$.

Fruits

Consumption of fruits more than 3 times/week reduces the risk of obesity in children $\{(\mathrm{p}=0.0003)$, OR $0.28,95 \% \mathrm{CI}=0.14-0.57\}$.

\section{Nuts and pulses}

Consumption of nuts and pulses more than 3 times/week $\{(\mathrm{p}=0.0028$, OR $0.13,95 \% \mathrm{CI}=0.03-0.5\}$ or at least $1-2$ times/week $\{(\mathrm{p}=0.0017, \mathrm{OR}$ $0.12,95 \% \mathrm{CI}=0.03-0.5\}$ reduces the risk of children becoming obese.

Table 1: Characteristics of children participated in study. Data were divided into four groups based on the BMI of children and their frequencies are calculated using Epi info software

\begin{tabular}{|c|c|c|c|c|c|}
\hline Characteristics & n (\%) & Normal - n (\%) & Obese - n (\%) & Over weight - n (\%) & Under weight - n (\%) \\
\hline \multicolumn{6}{|l|}{ Age (years) } \\
\hline $6-7$ & $111(32)$ & $22(26.1)$ & $26(41.9)$ & $8(22.2)$ & $54(32.9)$ \\
\hline $8-9$ & $120(34.6)$ & 28 (33.3) & $28(45.1)$ & $13(36.1)$ & 51 (31.1) \\
\hline $10-11$ & 99 (28.6) & $26(30.9)$ & $8(12.9)$ & $12(33.3)$ & 54 (32.9) \\
\hline 12 & $16(4.6)$ & $8(9.5)$ & $0(0)$ & $3(8.3)$ & $5(3.05)$ \\
\hline \multicolumn{6}{|l|}{ Sex } \\
\hline Boys & $159(45.9)$ & $42(50)$ & $20(32.2)$ & 15 (41.6) & $82(50)$ \\
\hline Girls & $187(54)$ & $42(50)$ & $42(67.7)$ & 21 (58.3) & $82(50)$ \\
\hline \multicolumn{6}{|l|}{ BMI } \\
\hline Frequency & & $84(24.2)$ & 62 (17.9) & $36(10.4)$ & $164(47.4)$ \\
\hline Total (346) & & 84 & 62 & 36 & 164 \\
\hline
\end{tabular}




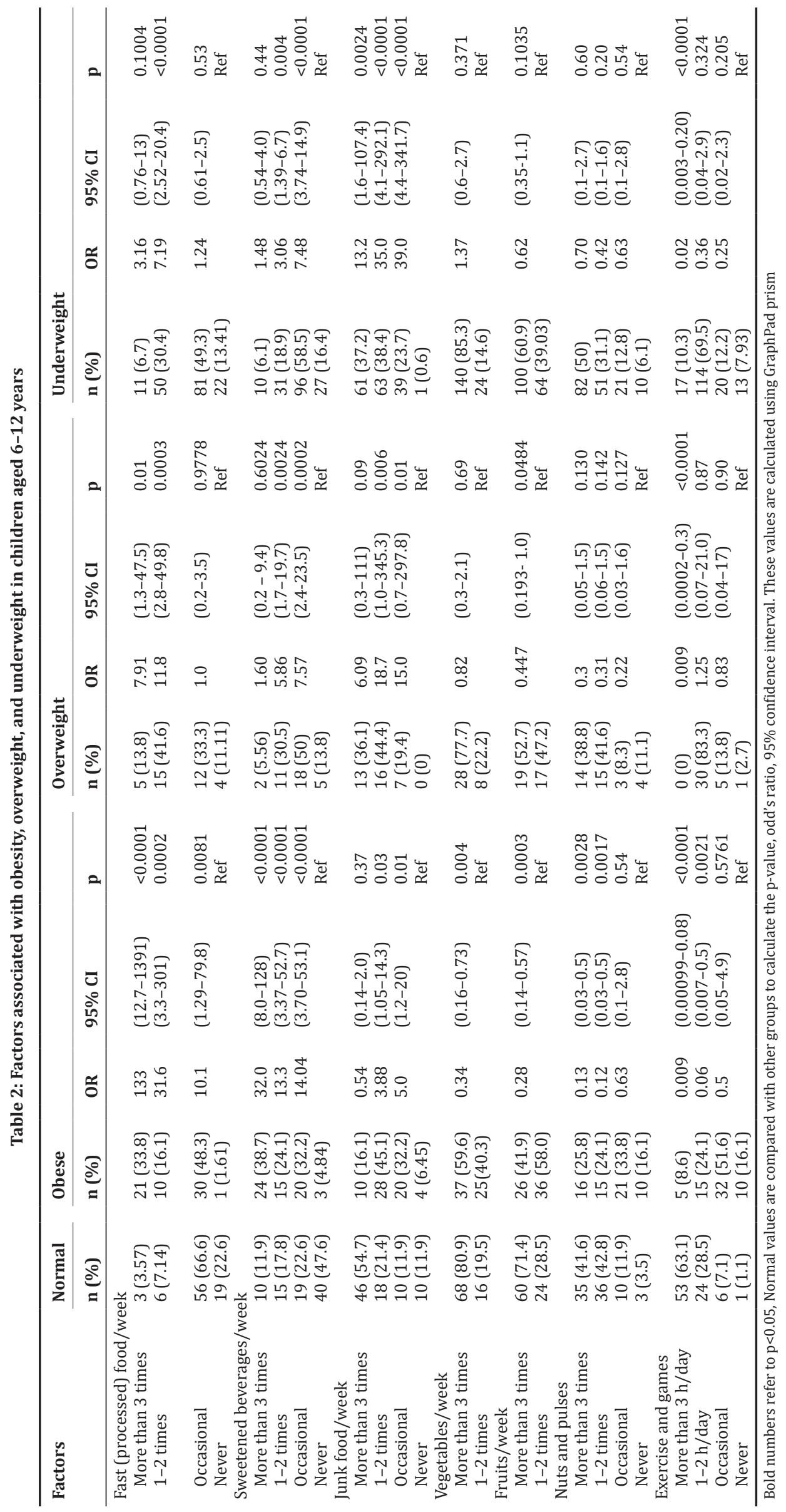




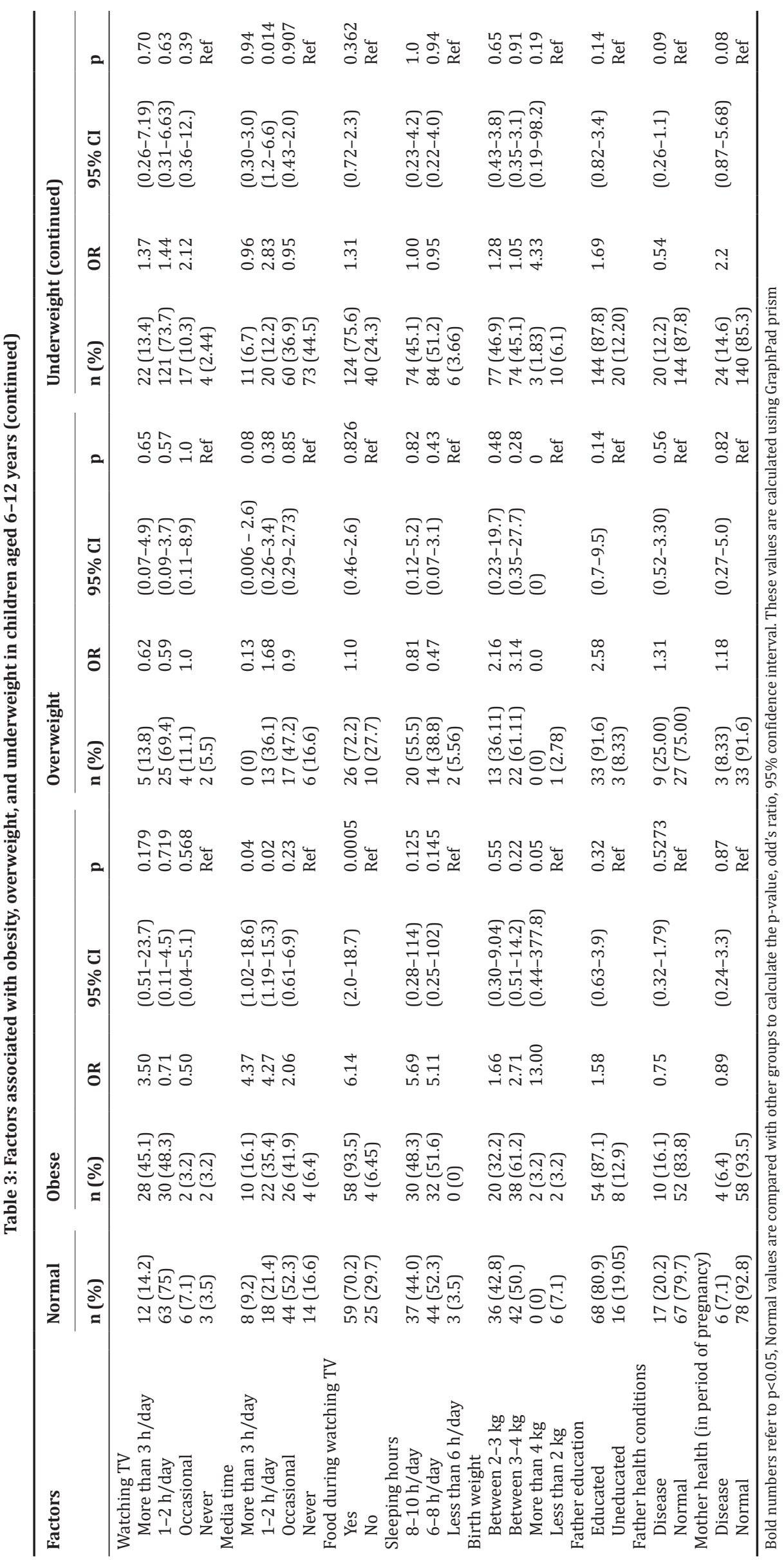


Exercise and games

Exercising and playing games more than $3 \mathrm{~h} /$ day $\{(\mathrm{p}<0.0001), 0 R 0.009$, $95 \% \mathrm{CI}=0.00099-0.08\}$ or at least $1-2 \mathrm{~h} /$ day $\{(\mathrm{p}=0.0021), 0 R 0.06$, $95 \% \mathrm{CI}=0.007-0.5\}$ reduces the risk of obesity in children.

Similarly, daily exercise and games for more than $3 \mathrm{~h}$ are found to reduce the risk of children becoming overweight $\{(\mathrm{p}<0.0001), 0 \mathrm{R}$ $0.009,95 \% \mathrm{CI}=0.0002-0.3\}$ and underweight $\{(\mathrm{p}<0.0001,0 \mathrm{R} 0.02,95 \%$ $\mathrm{CI}=0.003-0.20\}$.

\section{Media time}

From Table 3, time spent on digital or social media for more than $3 \mathrm{~h} /$ day $\{(\mathrm{p}=0.04, \mathrm{OR} 4.37,95 \% \mathrm{CI}=1.02-18.6\}$ or even $1-2 \mathrm{~h} /$ day $\{(\mathrm{p}=0.02)$, OR $4.27,95 \% \mathrm{CI}=1.19-15.3\}$ is found to be significantly associated with obesity in children. Furthermore, media time of $1-2 \mathrm{~h} /$ day was found to be significantly associated with underweight in children $\{(\mathrm{p}=0.014, \mathrm{OR}$ $2.83,95 \% \mathrm{CI}=1.2-6.6\}$. Interestingly, no association was found between watching TV and obesity, overweight or underweight in children.

\section{Food during watching television}

Although watching television alone has not produced any significant associations, taking food while watching television is found to be a significant risk factor associated with obesity among children. $\{(\mathrm{p}=0.0005$, OR 6.14, 95\% CI=2.0-18.7 $\}$.

Factors such as sleeping hours, birth weight, father's education, father's health, and mother's health during pregnancy were not associated with either of obesity, overweight, and underweight in this study.

\section{DISCUSSION}

Our findings from this research are used to determine the effect of factors on the occurrence of obesity, overweight, and underweight in children.

In this study, the overall prevalence of obesity, overweight, and underweight was $17.92 \%, 10.40 \%$, and $47.40 \%$, respectively. The incidence of underweight children is highest in India in a study that estimated worldwide trends in mean body mass index [15].

Fast foods or processed foods typically contain high amounts of calories and fat and this contributes to the incidence of obesity and overweight. The present study confirms that consumption of fast food can influence the BMI in children. Similarly, an international study conducted by Braithwaite et al. reported that frequent and very frequent fastfood consumption is associated with a higher BMI in children [16]. An association between fast food consumption and underweight is observed in this study. Fast foods may also suppress the appetite for a balanced diet including vegetables and fruits. This can be the possible explanation for the above-mentioned finding. The availability of a wide variety of fruits and vegetables and/or fussy eating behavior of children needs to be studied further

The present study confirms that taking sweetened beverages frequently have a high significant association with obesity in children. Sweetened beverages are found to increase the risk of overweight as well in children even when consumed occasionally. In a systematic-review undertaken by Malik et al., a positive association was observed between greater consumption of sugar sweetened beverages and weight gain and obesity in both children and adults. These findings were derived from large cross-sectional studies and prospective cohort studies with long periods of follow-up [17]. Interestingly, our study shows association between sweetened beverages and underweight in children. Another possible explanation is that sugary drinks make one feel full, thereby reducing the amount of food intake. Hence, disturbances in the regular diet and a decrease in the amount of nutrition are observed.

Junk food consumption is significantly associated with malnutrition or low BMI among adolescents [18]. This result is consistent with the findings of the present study, in which children who ate junk food are at increased risk of having low BMI. Nowadays, low cost and ease of availability make junk food a leading risk factor associated with BMI in children.

In a study conducted by Wall et al., an inverse association was observed between BMI and consumption of vegetables, fruits, nuts, and pulses [19]. In the present study, we can see that vegetables, fruits, pulses, and nuts consumption reduce the risk of obesity in children. Taking fruits more than thrice/week also reduce the risk of overweight significantly.

In a study conducted by Klein-Platat et al., inverse association between structured physical activity and BMI was observed but significantly only for girls $(\mathrm{p}<0.01)$ in 12-year-old French adolescents [20]. The present study confirms that children who are involved in exercise and games daily have a reduced risk of obesity and overweight dues to the inverse association as is clearly shown. Furthermore, in our study exercise and games are found to be inversely related to underweight in children. By contrast, underweight in children was significantly related to their physical activity ( $\mathrm{p}=0.006$ ), such as playing outdoors in a study conducted by Syahrul et al. [3].

The findings of this study did not show any significant association between watching television and BMI in children but time spent on media (digital or social media) has significant impact in the case of obesity in children. Some studies reported significance w.r.t screen time and electronic media [21,22]

In our study, consumption of food while watching television was associated with BMI in obese children. Similarly, a study conducted by Matheson et al., supports our findings. Avoiding television viewing while eating meals was associated with lower odds of obesity and overweight [23]. Besides, a few other studies also concluded that the children watching television while eating were prone to obesity/overweight $[24,25]$. Measures should be taken to reduce the food consumption during TV viewing as it may lead to unconsciousness intake of more calories and high-fat food.

Mother's education does not reflect any association with BMI in children in this study. Whereas, Syahrul et al. observed overweight to be prevalent among children whose mothers were highly educated in their study findings [3]. The present study has no association between sleeping hours of children and their BMI. A study conducted by Wang et al. reports sleep duration and later bed time as risk factors for obesity in childhood independently [26].

Weight at the time of birth is not associated with BMI in our study. However, a study undertaken in Istanbul, Turkey, by Vehapoglu et al. found that increased birth weight and maternal BMI as significant risk factors for obesity in children [27]. Factors such as father's education, father's health conditions, and mother's health conditions do not show any significant relation with BMI in children and further research is needed to support major public interventions.

\section{CONCLUSION}

The epidemic of obesity, overweight, and underweight is a serious public health issue in urban areas and rural areas. To prevent overweight and obesity, a population level approach should be adopted. From the factors, we opted to explore in this study; fast food, sweetened beverages, junk food, and consumption of food while watching television, media time indicated a significant relationship with body mass index. Vegetables, fruits, nuts, and pulses, exercise, and games showed inverse associations with obesity and underweight in children. Health care professionals should educate parents and children regarding healthy nutrition and regular physical activity. The implications of obesity, overweight, and underweight should be well explained to make desirable lifestyle modifications for a better future.

\section{ACKNOWLEDGMENT}

We thank the Head of the Department and Department of Pharmacy Practice staff for the suggestions and we would like to express our sincere 
gratitude to the principal of KVSR Siddhartha College of Pharmaceutical Sciences, Dr. Pinnamaneni Siddhartha Institute of Medical Sciences and Research Foundation's Institutional Ethics Committee for suggestions and support for completion of this work.

\section{AUTHORS' CONTRIBUTIONS}

All the authors contributed equally.

\section{CONFLICTS OF INTEREST}

None.

FUNDING

Nil.

\section{REFERENCES}

1. Mitchell EA, Stewart AW, Braithwaite I, Murphy R, Hancox RJ, Wall $\mathrm{C}$, et al. Factors associated with body mass index in children and adolescents: An international cross-sectional study. PLoS One 2017;12:280-5.

2. Camacho S, Ruppel A. Is the calorie concept a real solution to the obesity epidemic? Glob Health Action 2017;10:1289650.

3. Syahrul S, Kimura R, Tsuda A, Susanto T, Saito R, Ahmad F. Prevalence of underweight and overweight among school-aged children and it's association with children's sociodemographic and lifestyle in Indonesia. Int J Nurs Sci 2016;3:169-77

4. Andersen RE. The spread of the childhood obesity epidemic. CMAJ 2000;163:1461-2.

5. Karnik S, Kanekar A. Childhood obesity: A global public health crisis. Int J Prev Med 2012;3:1-7.

6. Vanderwall C, Clark RR, Eickhoff J, Carrel AL. BMI is a poor predictor of adiposity in young overweight and obese children. BMC Pediatr 2017; $17: 135$

7. World Health Organization. Obesity: Preventing and Managing the Global Epidemic. Geneva: World Health Organization; 2000.

8. Lobstein T, Baur L, Uauy R. Obesity in children and young people: A crisis in public health. Obes Rev 2004;5:4-85.

9. O'Dea JA, Wilson R. Socio-cognitive and nutritional factors associated with body mass index in children and adolescents: Possibilities for childhood obesity prevention. Health Educ Res 2006;21:796-805.

10. Hui LL, Nelson EA, Yu LM, Li AM, Fok TF. Risk factors for childhood overweight in 6-to 7-y-old Hong Kong children. Int J Obes Relat Metab Disord 2003;27:1411-8.

11. Bhat VN. Fast food consumption and body mass index. J Soc Sci 2016;12:129-35

12. Cantor J, Breck A, Elbel B. Correlates of sugar-sweetened beverages purchased for children at fast-food restaurants. Am J Public Health 2016;106:2038-41.

13. Field AE, Gillman MW, Rosner B, Rockett HR, Colditz GA. Association between fruit and vegetable intake and change in body mass index among a large sample of children and adolescents in the United States. Int J Obes Relat Metab Disord 2003;27:821-6.

14. Sahoo K, Sahoo B, Choudhury AK, Sofi NY, Kumar R, Bhadoria AS. Childhood obesity: Causes and consequences. J Family Med Prim Care 2015;4:187-92.

15. Bentham J, di Cesare M, Bilano V, Bixby H, Zhou B, Stevens GA, et al. Worldwide trends in body-mass index, underweight, overweight, and obesity from 1975 to 2016: A pooled analysis of 2416 population-based measurement studies in 128.9 million children, adolescents, and adults. Lancet 2017;390:2627-42.

16. Braithwaite I, Stewart AW, Hancox RJ, Beasley R, Murphy R, Mitchell EA, et al. Fast-food consumption and body mass index in children and adolescents: An international cross-sectional study. BMJ Open 2014; 4:e005813.

17. Malik VS, Schulze MB, Hu FB. Intake of sugar-sweetened beverages and weight gain: A systematic review. Am J Clin Nutr 2006;84:274-88.

18. Poudel P. Junk food consumption and its association with body mass index among school adolescents. Int J Nutr Food Sci 2018;7:90.

19. Wall CR, Stewart AW, Hancox RJ, Murphy R, Braithwaite I, Beasley R, et al. Association between frequency of consumption of fruit, vegetables, nuts and pulses and BMI: Analyses of the international study of asthma and allergies in childhood (ISAAC). Nutrients 2018;10:316.

20. Klein-Platat C, Oujaa M, Wagner A, Haan MC, Arveiler D, Schlienger JL, Simon C. Physical activity is inversely related to waist circumference in 12-y-old French adolescents Int J Obes (Lond) 2005;29:9-14.

21. Li L, Shen T, Wen LM, Wu M, He P, Wang Y, et al. Lifestyle factors associated with childhood obesity: A cross-sectional study in Shanghai, China. BMC Res Notes 2015;8:6.

22. Melkevik O, Haug E, Rasmussen M, Fismen AS, Wold B, Borraccino A, et al. Are associations between electronic media use and BMI different across levels of physical activity? BMC Public Health 2015;15:497.

23. Matheson DM, Killen JD, Wang Y, Varady A, Robinson TN. Children's food consumption during television viewing. Am J Clin Nutr 2004;79:1088-94.

24. Vik FN, Bjørnarå HB, Øverby NC, Lien N, Androutsos O, Maes L, et al. Associations between eating meals, watching TV while eating meals and weight status among children, ages 10-12 years in eight European countries: The energy cross-sectional study. Int J Behav Nutr Phys Act 2013;10:58.

25. Ghobadi S, de Zepetnek JO, Hemmatdar Z, Bellissimo N, Barati R, Ahmadnia $\mathrm{H}$, et al. Association between overweight/obesity and eating habits while watching television among primary-school children in the city of Shiraz, Iran. Public Health Nutr 2018;21:571-9.

26. Wang J, Adab P, Liu W, Chen Y, Li B, Lin R, et al. Prevalence of adiposity and its association with sleep duration, quality, and timing among 9-12-year-old children in Guangzhou, China. J Epidemiol 2017;27:531-7.

27. Vehapoglu A, Goknar N, Turel O, Torun E, Ozgurhan G. Risk factors for childhood obesity: Do the birth weight, type of delivery, and mother's overweight have an implication on current weight status? World J Pediatr 2017;13:457-64. 